\title{
Body composition of preschool children and relation to birth weight
}

Thais Costa Machado ${ }^{1}$, Viviane G. Nascimento ${ }^{2}$, Janaína P. C. da Silva ${ }^{1 *}$, Ciro João Bertoli ${ }^{3}$, Claudio Leone ${ }^{4}$

'Masters in Public Health, PhD graduate student in Public Health, Department of Maternal and Child Health at the School of Public Health, University of São Paulo (FSP/USP), São Paulo, SP, Brazil.

"PhD in Public Health, PhD researcher of the Department of Maternal and Child Health at FSP/USP, and professor at Paulista University (UNIP), São Paulo, SP, Brazil.

${ }^{3}$ M.D. in the Department of Pediatrics at USP Medical School (FMUSP) and professor of the Department of Medicine at University of Taubaté (Unitau), Taubaté, SP, Brazil.

${ }^{4} \mathrm{PhD}$ and full professor (Livre-docente) in Pediatrics, Department of Pediatrics, FMUSP; associate professor of the Department of Pediatrics at FMUSP, and titular professor of the Department of Maternal and Child Health at FSP/USP, São Paulo, SP, Brazil.

Work carried out at the Department of Maternal and Child Health, School of Public Health, University of São Paulo (FSP/USP), São Paulo, SP, Brazil.

Article received: 10/2/2012 Accepted for publication: 9/11/2013

*Correspondence: Address: Av. Dr. Arnaldo, 715 São Paulo, SP, Brazil

ZIP Code: 01246-904 Phone: +55 11 3061-7974 jsilva@usp.br

http://dx.doi.org/10.1590/1806-9282.60.02.011 Conflict of interest: none

\section{Abstract}

Objective: to evaluate the relationship between body composition of preschool children suffering from excess weight and birth weight (BW).

Methods: probabilistic sample, by conglomerates, with 17 daycare centers (of a total of 59) composing a final sample of 479 children. We used Z-score of Body Mass Index (zBMI) $\geq+1$ and $\geq+2$, respectively, to identify preschool children with risk of overweight and excess weight (overweight or obesity). The arm muscle area (AMA) and the arm fat area (AFA) were estimated from measurements of arm circumference, triceps skin fold thickness.

Results: the prevalence of risk of overweight was $22.9 \%(n=110)$ and excess weight was $9.3 \%(n=44)$. The risk of overweight and excess weight in children did not show correlation between BW and AFA, but it did with adjusted arm muscle area (AMAa) $\left(\mathrm{r}_{\mathrm{p}}=0.21 ; \mathrm{p}=0.0107\right)$. The analysis of the group with excess weight alone also showed a positive correlation between BW and AMAa $\left(\mathrm{r}_{\mathrm{P}}=0.42 ; \mathrm{p}=0.0047\right)$.

Conclusion: among overweight children, lower BW is associated with a lower arm muscle area in early preschool age, regardless of the fat arm area presented by them.

Key words: body composition, preschool, birth weight, excess weight.

\section{INTRODUCTION}

Birth weight reflects, among other things, intrauterine growth and nutritional status of the newborn, being regarded as a separate indicator of health that can influence the growth and development of the child, in the medium and long term, also affecting the health conditions in adulthood. ${ }^{1}$ In this sense, overweight and obesity, described as having an increasing prevalence in the population and now also affecting very young children, even in families of lower socioeconomic status, in several studies, have been linked to birth weight. $^{2-5}$

Research has also shown that low birth weight is associated with the development of chronic noncommunicable diseases in adulthood, especially when due to intrauterine growth restriction (IUGR) and excess weight in childhood. ${ }^{6-9}$ According to Martins and Carvalho, ${ }^{10}$ among the various factors that have been linked to overweight and obesity in childhood, birth weight appears all too often.

Other factors that would be determinant of risk of excess weight are significant catch-up growth in the first 2 years of life ${ }^{9}$ and body composition. The latter would modify the body's ability to deal with glucose metabolism, ${ }^{8,11}$ especially when there is reduction in muscle mass. ${ }^{12,13}$

Barker et al. ${ }^{6,7}$ proposed several hypotheses to explain the observed association between IUGR, commonly measured by low birth weight, and the reduced 
lean body mass that these children may have. The first hypothesis is that, in situations of stress during pregnancy, the development of vital organs like the brain would be favored at the expense of muscle tissue. The second suggests that fetal hypoglycemia due to insufficient glucose supply would cause a reduction in insulin secretion that, in turn, would stimulate protein breakdown. The last hypothesis is that poor fetal nutrition would reduce the concentration of insulin-like growth factor type 1 (IGF-1), thereby undermining the growth of muscle mass.

Singhal et al., ${ }^{12}$ in a study of adolescents, showed that an increase of the order of one standard deviation in birth weight was associated with $2 \%$ to $3 \%$ increase in lean body mass without corresponding increase in fat mass. Since muscles are important "organs" for glucose metabolism, "metabolic programming" that results in a reduction in muscle mass would be able to cause insulin resistance.

This would be one possible mechanism by which low birth weight due to IUGR would be associated with increased risk of developing chronic noncommunicable diseases in adulthood. ${ }^{12,13}$

Considering the importance of early detection of risk for overweight/obesity, and its possible relation with a lower birth weight and lower lean mass, this study was conducted to evaluate the relationship between birth weight and body composition in preschool children with excess weight.

\section{Methods}

Cross-sectional study with preschoolers aged 2 to less than 4 years, enrolled and attending daycare centers in the city of Taubaté, São Paulo, Brazil. The sampling was probabilistic and random, by clusters, from a list of 59 daycare centers provided by the Department of Education and Culture of the City of Taubaté, in the state of São Paulo, Brazil, so that 17 were randomly selected to compose a final study sample.

In order to calculate the size of the sample, an expected prevalence of at least $25 \%$ for excess weight was used, estimated to have an accuracy of $5 \%$ for a level of significance $(\alpha)$ of 0.05 and test power $(1-\beta) 0.80$, leading to a required minimum sample size of 528 preschoolers.

The sample of randomly selected daycare centers included a total of 534 children. The data collection period was from September of 2008 to March of 2010. All children in the sample had the consent of parents or guardians to participate in the study. Of the initial sample, 55 children (10.3\%) who had a low birth weight or whose weight at birth was above $4.5 \mathrm{~g}$ were excluded, changing the total number of children in the final sample to 479 .

From a total of 479 children and estimating a confidence interval of $95 \%$ (for $80 \%$ statistical power), it was found that the final sample would discriminate 4-percentage point differences, which was considered adequate for the study, with no need to replace the 55 children excluded, corresponding to $10.3 \%$ of the initially selected sample.

Birth weight (BW) and birth length (BL) of these children were collected through standardized forms, derived from three sources: the register of the Municipal University Maternity Hospital; the child's card, which is attached to the daycare center's enrollment forms; and, if necessary, information provided by mothers and/or guardians of the child, in order to diminish the losses caused by the lack of this information. Retrieving information on gestational age was not possible and therefore no assessment of appropriateness of weight and birth length was performed. In the analysis, we chose to operationalize birth weight (in grams), birth length (in centimeters) and weight:length ratio at birth $(\mathrm{g} / \mathrm{cm})$ on an ongoing basis.

All children underwent anthropometric assessment in their own daycare centers, recording weight, height, arm circumference (AC) and triceps skin fold thickness (TST). The measurements were performed by nutritionists and medical students previously trained in accordance with the standards of the World Health Organization (WHO). ${ }^{14}$

The anthropometric measurements were performed at the daycare centers, on days previously scheduled. For weighing, a portable digital scale SECA ${ }^{\circledR}$ (Seca ( 803 ) was used, with a capacity of $150 \mathrm{~kg}$ and $100 \mathrm{~g}$ precision. Children were weighed without shoes and in light clothing. Height was obtained using portable stadiometer WISO ${ }^{\circledR}$, wall mounted, standardized in centimeters and millimeters. The children's height was measured without shoes and without hair ornaments; they were placed standing up, with arms outstretched at their sides, shoulders relaxed, heels put together, and aligned with the Frankfurt horizontal plane. ${ }^{14}$

AC was obtained by a tape measure with a thickness of $0.5 \mathrm{~cm}$, surrounding the arm, without pressing the midpoint of the nondominant arm between the acromion and the olecranon, with the child standing, and arms relaxed along the body. ${ }^{13}$ 
The measurement of triceps skin fold thickness (TST) was taken with a LANGE $®$ skin fold caliper, with constant pressure at the midpoint of the dorsal surface of the non-dominant arm in the triceps area. ${ }^{14}$ The fold of skin was measured twice, so that, if there was discrepancy between the two measurements, the procedure would be performed again. Thereafter, for purposes of analysis, the average of the recorded values was used for each child.

To point out the children at risk of being overweight, we used a cut off $\geq+1$ for the $Z$ score of body mass index (zBMI) and, in order to identify those with excess weight (overweight or obese), the cutoff $\geq+2 \mathrm{zBMI}$ was used as the reference values adopted by the WHO $(2006)^{15}$ and the guidelines of both the Ministry of Health (2009) ${ }^{16}$ and the WHO. ${ }^{17}$

The arm muscle area (AMA) and arm fat area (AFA) were estimated based on mathematical formulas by Rolland-Cachera et al., ${ }^{18}$ using triceps skin fold and arm circumference measures. The correction of AMA (AMAa), used in this study, follows the proposition of Heymsfield et al. ${ }^{19}$ being proportionally adjusted to this population.

For statistical analysis, Medcalc ${ }^{\circledR}$ (9.3.9.0 version) and SPSS ${ }^{\circledR}(15.0$ version) softwares were used. Frequencies, proportions and means were calculated according to their relevance, with subsequent estimate of their associations. We opted to use the significance level of 0.05 and, where appropriate, confidence intervals (CI) of $95 \%$ were also estimated.

This study was in accordance with resolution CNS 196/96, and was approved by the Ethics Committee in Research of the University of (CEP/Unitau), no. 0002/05, and the Research Ethics Committee of the School of Public Health, at University of São Paulo (protocol n ${ }^{\circ}$ 361/09).

\section{Results}

The mean age of the final sample was 3.3 years, with a standard deviation (SD) of 0.3 years. Of the total number of children assessed, 53.9\% $(\mathrm{n}=258)$ were male.

The prevalence of normal weight was at $67.8 \%$ ( $\mathrm{n}=$ $325)$, with risk for overweight at $22.9 \%(\mathrm{n}=110)$ and excess weight at $9.3 \%(n=44)$.

In the group of preschoolers at risk for overweight, overweight and obesity, we observed that $52 \%$ of children were female.

When comparing the group of preschool children without nutritional disorders with the risk of over- weight or excess weight, it was found that there was no significant difference in terms of age $(p=0.645)$ and birth weight $(\mathrm{p}=0.370)$.

The arm muscle area (AMA) $(p=0.002)$, arm fat area (AFA) ( $\mathrm{p}<0.001$ ) and $z B M I$ ( $\mathrm{p}<0.0001$ ), as expected, showed significant differences between the groups at risk of being overweight or presenting excess weight.

In the final sample $(n=479)$, there was a positive correlation between birth weight and $\mathrm{zBMI}\left(\mathrm{r}_{\mathrm{p}}=0.23\right.$; $\mathrm{p}<$ $0.0001)$ and birth length $\left(r_{p}=0.16 ; p=0.0004\right)$, as well as the weight:length ratio at birth $\left(r_{p}=0.20 ; p<0.0001\right)$.

In 154 children at risk for overweight or excess weight, a positive correlation was observed between $z B M I$ and AMAa $\left(r_{p}=0.33 ; p<0.0001\right)$ and AFA $\left(r_{p}=0.74 ; p<0.0001\right)$. Nevertheless, zBMI was not correlated with weight at $\operatorname{birth}\left(r_{p}=0.04 ; p=0.62\right)$.

Figure 1 shows the positive correlation between birth weight and AMAa $\left(r_{p}=0.21 ; p=0.0107\right)$, observed in the group of children at risk for overweight and excess weight. In both groups, there was a positive correlation between birth weight and unadjusted AMA $\left(r_{p}=\right.$ $0.21 ; p=0.0086)$, even though no correlation was observed between birth weight and AFA $\left(r_{p}=-0.13\right.$; $p=$ 0.1082).

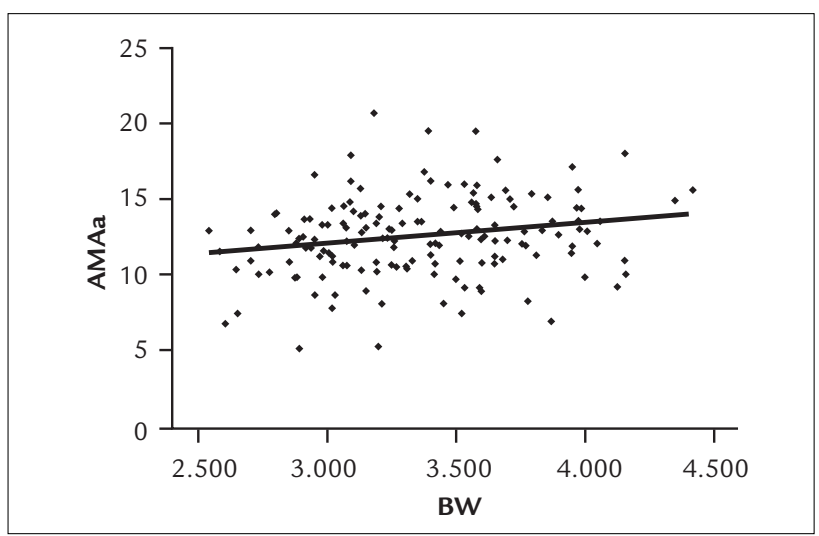

FIGURE 1 Correlation between birth weight (BW) and adjusted arm muscle area (AMAa) in preschool children at risk for overweight and excess weight.

The analysis that only included the group of children with excess weight revealed a positive correlation between birth weight and both adjusted AMA $\left(r_{p}=0.42 ; p=0.0047\right)(F i-$ gure 2$)$ and non adjusted AMA $\left(r_{p}=0.43 ; p=0.0033\right)$, even though there was no evident correlation between birth weight and AFA measures $\left(r_{p}=-0.20 ; p=0.1854\right)$. 


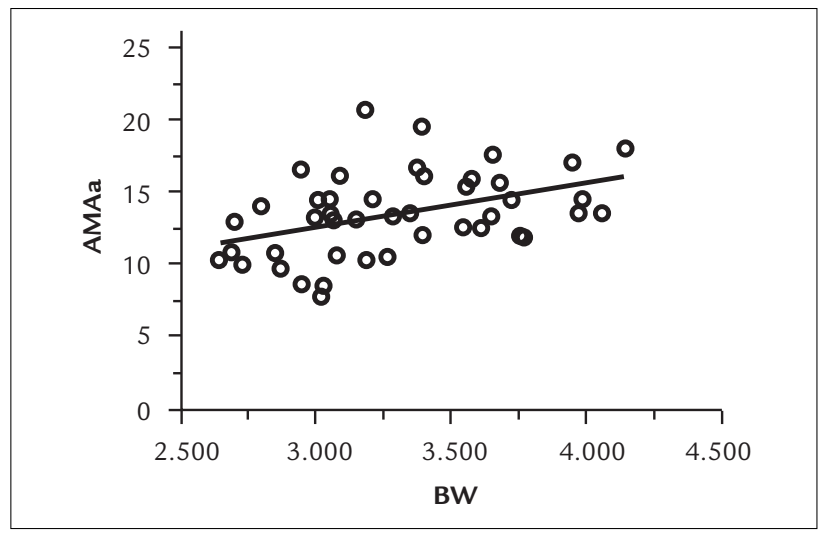

FIGURE 2 Correlation between birth weight (BW) and adjusted arm muscle area (AMAa) of preschool children with excess weight (overweight or obese).

Figure 3 shows that, in the group of preschool children at risk for overweight or with excess weight, there was no correlation between AFA and AMAa $\left(r_{p}=0.0110 ; p=0.8923\right)$.

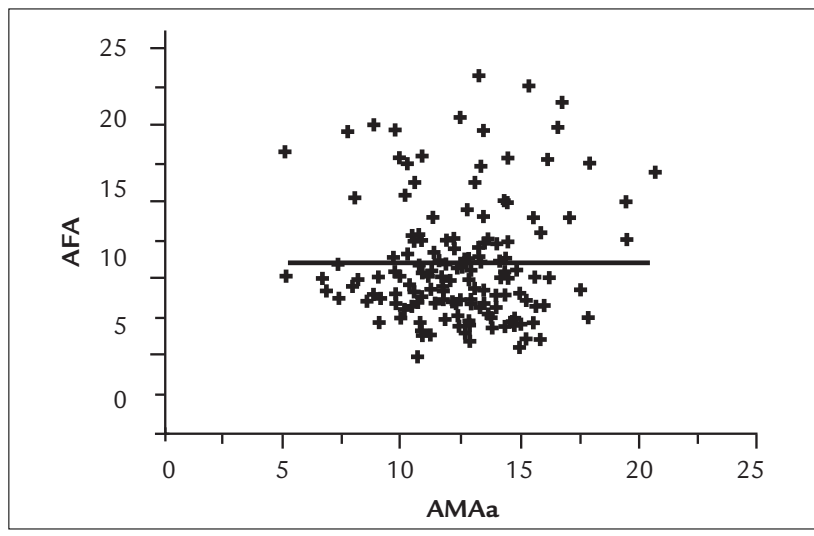

FIGURE 3 Correlation between the adjusted arm muscle area (AMAa) and arm fat area (AFA) of preschool children at risk for overweight and excess weight.

\section{Discussion}

In this study, in preschoolers at risk for overweight or excess weight, birth weight was directly associated with the adjusted arm muscle area (AMAa), regardless of the arm fat area (AFA) displayed by the child, even if there was no association between birth weight and zBMI in the preschool age range.

Less lean body mass has been described in several studies as a risk factor equivalent to visceral fat for the development of changes in glucose metabolism and chronic noncommunicable diseases in adulthood. ${ }^{12,13,19,21}$ Many studies about the relationship between weight at birth and body composition have been conducted with chil- dren, adolescents and/or adults, ${ }^{10,22,23}$ but, with respect to the beginning of the preschool age, we found only two studies on the relationship between birth weight and lean mass - both conducted in developed countries. ${ }^{24,25}$

Hediger et al. ${ }^{24}$ found that the arm muscle area (AMA) was lower in children born small for gestational age (SGA) when compared to large for gestational age (LGA). Similar results were observed in this study, i.e., lower birth weight was related to lower AMA. However, no association was found between birth weight and AFA, unlike the observations made by Hediger et al. ${ }^{24}$ that AFA was associated with birth weight, being lower in SGA. Still according to these authors, the weight at birth was more weakly associated with AFA compared with AMA. Another study showed that children born SGA also had less lean body mass, despite having more fat mass compared with children appropriate for gestational age (AGA). Both groups (SGA and LGA) had similar weight gain and BMI. ${ }^{25}$

A limitation of this study was that it was not possible to retrieve information on the gestational age of a part of the children included in the sample. But even though this has made almost impossible to compare this work in more detail with the aforementioned studies, the validity of the results observed in this study, as well as the trends indicated by it, were certainly not compromised.

As for studies in later life, a survey among school children also found no relationship between birth weight and proportion of body fat mass, but noted a positive correlation between birth weight and lean mass in these children. ${ }^{20}$ Similar results were also observed in other studies with preadolescents ${ }^{20}$ and adults. ${ }^{12}$ These data suggest that other factors, such as weight gain in the first year of life and/or a genetic predisposition, ${ }^{22,26}$ would be associated with the development of a greater amount of body fat in childhood.

Regarding the Barker hypothesis, ${ }^{6,7}$ there seems to be consensus on the relationship between birth weight and lean body mass, regardless of age group, but the relationship with fat mass remains controversial.

All these facts, together with the results of this study reinforce the initial hypothesis that there is indeed a positive association between birth weight and arm muscle area of preschool children, which is indicative of the existence of this very association with lean body mass.

AMA, a measure to estimate lean mass, seems to be a more consistent indicator than the single use of BMI for assessing possible risks of overweight in childhood. The importance of this consideration is reinforced by the fact 
that our results show no association between birth weight and BMI in preschool children presenting excess weight or who are obese.

Thus, even considering the relationship between lean mass and 'metabolic changes in the body', as described in the literature, evaluating the AMA becomes even more important in the routine of child care.

If future research confirms these correlations, the AMA will become an important marker of risk for developing or maintaining obesity until early adulthood, with all of its consequences. This is particularly important for children who are born with lower weight and become overweight as early as in the beginning of the preschool age, which would justify even the adoption of AMA assessment as part of these children's routine care.

This research was funded by the São Paulo Research Foundation - FAPESP, process no. 08/53142-9.

\section{Resumo}

Objetivo: avaliar a relação entre a composição corporal de pré-escolares portadores de excesso de peso e o seu peso ao nascimento (PN).

Métodos: amostra probabilística, por conglomerados, com 17 creches (de um total de 59), composta por 479 crianças. Para identificar os pré-escolares portadores de risco de sobrepeso e de excesso de peso (sobrepeso ou obesidade), utilizou-se o escore $Z$ de índice de massa corpórea $(z I M C) \geq+1$ e $\geq+2$, respectivamente. A área muscular do braço corrigida (AMB) e a área gorda do braço (AGB) foram estimadas a partir das medidas de circunferência do braço e da dobra cutânea tricipital.

Resultados: a prevalência de risco de sobrepeso foi de $22.9 \%(n=110)$ e de excesso de peso de 9.3\% ( $n=44)$. Juntas, as crianças com risco de sobrepeso e excesso de peso não mostraram correlação entre o PN e a área gorda do braço, mas, sim, com a área muscular do braço corrigida $(\mathrm{AMBc})\left(\mathrm{r}_{\mathrm{P}}=0.21 ; \mathrm{p}=0.0107\right)$. A análise só do grupo com excesso de peso também evidenciou correlação positiva entre $\mathrm{PN}$ e $\mathrm{AMBc}\left(\mathrm{r}_{\mathrm{P}}=0.42 ; \mathrm{p}=0.0047\right)$.

Conclusão: nas crianças com excesso de peso, um menor PN está associado a uma menor área muscular do braço no início da idade pré-escolar, independentemente da área gorda do braço que elas apresentem.

Unitermos: composição corporal, pré-escolar, peso ao nascer, excesso de peso.

\section{RefERENCES}

1. Wilcox AJ. On the importance and the unimportance of birth weight. Int J Epidemiol 2001; 30:1233-41.

2. Raj M, Sundaram KR, Paul M, Sudhakar A, Kumar RK. Dynamics of growth and weight transitions in a pediatric cohort from India. Nutr J 2009; 8:55.

3. Nascimento VG, Bertoli CJ, Bertoli LMQ, Feferbaun R, Abreu LC, Leone C. Tendência secular de crescimento de crianças pré-escolares, Brasil, 1997 2007. Rev Bras Crescimento Desenvolv Hum 2010; 20:199-207.

4. Shoeps DO, Abreu LC, Valenti VE, Nascimento VG, Oliveira AG, Gallo PR et al. Nutritional status of pre-school children from low income families. Nutr J 2011; 10:43

5. Nascimento VG, Shoeps DO, Souza SB, Souza JMP, Leone C. Risco de sobrepeso e excesso de peso em crianças de pré-escolas privadas e filantrópicas. Rev Assoc Med Bras 2011; 57:657-61.

6. Barker DJ, Bull AR, Osmond C, Simmonds SJ. Fetal and placental size and risk of hypertension in adult life. BMJ. 1990;301:259-62.

7. Barker DJ, Hales CN, Fall CH, Osmond C, Phipps K, Clark PM. Type 2 (non-insulin-dependent) diabetes mellitus, hypertension and hyperlipidaemia (syndrome $\mathrm{X}$ ): relation to reduced fetal growth Diabetologia 1993; 36:62-7

8. Wilkin TJ, Metcalf BS, Murphy MJ, Kirkby J, Jeffery AN, Voss LD. The relative contributions of birth weight, weight change, and current weight to insulin resistance in contemporary 5-year-olds: the EarlyBird Study. Diabetes 2002; 51:3468-72.

9. Ong KK, Ahmed ML, Emmett PM, Preece MA, Dunger DB. Association between postnatal catch-up growth and obesity in childhood: prospective cohort study. BMJ 2000; 320:967-71

10. Martins EB, Carvalho MA. Associação entre peso ao nascer e o excesso de peso na infância: revisão sistemática. Cad Saúde Pública 2006; 22:2281 300.

11. Ong KK, Dunger DB: Birth weight, infant growth and insulin resistance. Eur J Endocrinol 2004; 151(Suppl 3):U131-9.

12. Singhal A, Wells J, Cole TJ, Fewtrell M, Lucas A. Programming of lean body mass: a link between birth weight, obesity, and cardiovascular disease? Am J Clin Nutr 2003; 77:726-30

13. Ylihärsilä H, Kajantie E, Osmond C, Forsén T, Barker DJP, Eriksson JG. Birth size, adult body composition and muscle strength in later life. Int J Obes (Lond). 2007;31:1392-9.

14. World Health Organization. Physical status: the use and interpretation of anthropometry. Report of a WHO Expert Committee. Geneva; 1995.

15. World Health Organization. Child growth standards based on length/ height, weight and age. Acta Paediatr 2006; 450 (Suppl):76-85.

16. Ministério da Saúde. Departamento de Atenção Básica. SISVAN. Disponível em: http://nutricao.saude.gov.br $\backslash$ sisvan.php?conteudo=curvas_cresc_oms.

17. De Onis M, Lobstein T. Defining obesity risk status in the general childhood population: Which cut-off should we use? Int J Pediatr Obes 2010; 5:458 60 .

18. Rolland-Cachera MF, Brambilla P, Manzoni P, Akrout M, Sironi S, Maschio $\mathrm{AD}$, Chiumello G. Body composition assessed on the basis of arm circumference and triceps skin fold thickness: a new index validated in children by magnetic resonance imaging. Am J Clin Nutr 1997; 65:1709-13.

19. Heymsfield SB, McManus C, Smith J, Stevens V, Nixon DW. Anthropometric measurement of muscle mass: revised equations for calculating bone-free arm muscle area. Am J Clin Nutr 1982; 36:680-90.

20. Kelly LA, Lane CJ, Ball GD, Weigensberg MJ, Vargas LG, Byrd-Williams $\mathrm{CE}$ et al. Birth weight and body composition in overweight Latino youth: a longitudinal analysis. Obesity 2008; 16:2524-8.

21. Wells JC, Hallal PC, Wright A, Singhal A, Victora CG. Fetal, infant and childhood growth: relationships with body composition in Brazilian boys aged 9 years. Int J Obes (Lond) 2005; 29:1192-8.

22. Ong KK. Size at birth, postnatal growth and risk of obesity. Horm Res 2006; 65(Suppl. 3):65-9.

23. Mori M, Mori H, Yamori Y, Tsuda K. Low birth weight as cardiometabolic risk in Japanese high school girls. J Am Coll Nutr 2012; 31:39-44. 
24. Hediger ML, Overpeck MD, Kuczmarski RJ, McGlynn A, Maurer KR, Davis WW. Muscularity and fatness of infants and young children born smallor large-for-gestational-age. Pediatrics 1998; 102(5):e60.

25. Ibáñez L, Ong K, Dunger DB, De Zegher F. Early development of adiposity and insulin resistance after catch-up weight gain in small-for-gestationalage children. J Clin Endocrinol Metab 2006; 91(6):2153-8.
26. Baker JL, Michaelsen KF, Rasmussen KM, Sorensen TI. Maternal prepregmant body mass index, duration of breastfeeding, and timing of complementary food introduction are associated with infant weight gain. Am J Clin Nutr 2004; 80:1579-88. 